\title{
A Virtude do Erro: uma visão construtiva da avaliação
}

\author{
ELEONORA MARIA DINIZ DA SILVA \\ Professora, psicóloga, especialista em Psicopedagogia e Avaliação \\ noradins@gmail.com
}

\begin{abstract}
Resumo
Este trabalho discorre sobre o "erro" que surge no percurso da construção do conhecimento, tanto de alunos quanto de professores, reconhecidos como protagonistas da história da aprendizagem. Procura estruturar a revisão e análise das práticas pedagógicas e da avaliação, caracterizando diferentes perspectivas que marcam a sua evolução no decorrer da história humana e da educação. Com base em contribuições de pesquisas e estudos já realizados, traça uma abordagem metodológica para uma avaliação construtiva, enfatizando aspectos qualitativos e sua função formativa. Apóia-se, também, na concepção psicopedagógica que integra os aportes teóricos da Psicologia Genética, da Psicanálise e da Psicologia Social, numa visão interdisciplinar. Considera que no desvendar do erro reside a possibilidade de resgate da premissa básica da avaliação, o questionamento, que leva à transformação do significado restritivo, comumente a ela atribuído, para um significado construtivo, que favorece o crescimento de todos os envolvidos nesse processo, por meio do desenvolvimento de uma "cultura da avaliação". Aponta para a metavaliação como via de reflexão crítica e coletiva para superar as dificuldades e compreender os erros que fazem parte do caminho da construção do conhecimento, bem como do próprio processo de avaliação.
\end{abstract}

Palavras-chave: erro, aprendizagem, avaliação construtiva, metavaliação.

\section{Resumen}

Este trabajo discurre sobre el "error" surgido en el proceso de construcción del conocimiento, tanto de los alumnos como de los profesores, en tanto protagonistas de la historia del aprendizaje. Intenta estructurar la revisión y el análisis de las prácticas pedagógicas y de evaluación, tomando y caracterizando diferentes perspectivas que marcan su evolución a lo largo de la historia y de la educación. Basándose en contribuciones de investigaciones y estudios anteriores, propone un abordaje metodológico para una evaluación constructiva, enfatizando los aspectos cualitativos y su función formativa. Se apoya también en la concepción psicopedagógica que integra, en una visión interdisciplinar, los aportes teóricos de la Psicología Genética, del Psicoanálisis y de la Psicología Social. Considera que revelar el error permite rescatar la premisa básica de la evaluación: el cuestionamiento. Esto produce la transformación del significado restrictivo, comunmente atribuido a la evaluación, en otro constructivo que favorece el crecimiento de todos los involucrados en este proceso, a través del desarrollo de una "cultura de la evaluación". Apunta también a la metaevaluación como vía de reflexión crítica y colectiva para superar las dificultades y comprender los errores que forman parte del camino de la construcción del conocimiento, así como del propio proceso de evaluación.

Palabras clave: error, aprendizaje, evaluación constructiva, metaevaluación. 


\begin{abstract}
This article discusses the "error" that comes up in the course of building knowledge, both by students and teachers, who are the actors in the history of learning. It aims at structuring a review and an analysis of pedagogical practices and evaluation, characterizing different perspectives that mark their evolution throughout human history and the history of education. Based on contributions of research and studies already carried out, it traces a new methodological approach for a constructive evaluation, emphasizing qualitative aspects and their formative function. It is also supported by theoretical assumptions from Psychopedagogy, which integrate concepts of Genetic Psychology, Psychoanalysis and Social Psychology, in a interdisciplinary perspective. It considers that it is in unveiling the error that resides the possibility to rescue evaluation's basic premise - questioning -, leading to the transformation of a restrictive meaning, usually attributed to it, into a constructive meaning, that favors the growth of everyone involved in this process, through the development of a "culture of evaluation". It points to meta-evaluation as a way of critical and collective reflection to overcome the difficulties and understand the errors that are an inherent part of the construction of knowledge as well as of the process of evaluation itself. Key words: error, learning, constructive evaluation, metaevaluation.
\end{abstract}




\section{INTRODUÇÃO}

\section{Justificativa}

Muito se tem dito a respeito dos índices de repetência e evasão, como evidências do fracasso escolar, principalmente nas escolas públicas brasileiras.

Perplexos diante dessa situação, educadores têm-se dedicado a resolver o problema. Entre as várias soluções propostas, critérios de avaliação oscilam da extrema rigidez, buscando selecionar os "bons" alunos que justificariam os investimentos feitos em educação, para critérios extremamente fluidos e complacentes, enfatizando a democratização do ensino, visando a manter nas escolas, pelo maior tempo possível, alunos das classes populares.

A prática da avaliação do aproveitamento do aluno tem sido pautada pela busca da objetividade e precisão de instrumentos e critérios utilizados (Bradfield, 1963; Popham, 1976, 1977; Medeiros, 1977; Lindeman, 1978; Soeiro, 1982). O enfoque predominante é o da pedagogia do exame, como diz Cipriano Luckesi (1995), cujo interesse está centrado na aprovação/reprovação dos alunos. $\mathrm{O}$ ato de avaliar, dessa maneira, tem como propósito principal a classificação.

Atualmente essa avaliação tradicional vem sendo alvo de muitos questionamentos. Hoje, constata-se que existem muitos caminhos possíveis para a prática da avaliação. Mas qual deles deve-se considerar como desejável diante da atual realidade e exigências dos novos tempos?

A resposta a esta questão conduz a profunda reflexão não só acerca da avaliação como prática pedagógica, mas também, e principalmente, a respeito da escola, da educação e ainda a respeito da sociedade. Uma análise da avaliação educacional envolve a avaliação da própria instituição de ensino que deixa transparecer em sua prática pedagógica a concepção de aprendizagem e de homem que adota, assim como a ideologia que abraça; enfim, a visão de mundo que tem e representa e que intenta transmitir na formação de seus alunos. Segundo Luckesi, (...) para que a avaliação educacional escolar assuma o seu verdadeiro papel de instrumento dialético de diagnóstico para o crescimento, terá de se situar e estar a serviço de uma pedagogia que esteja preocupada com a transformação (...) (1995, p. 42).

A avaliação, numa visão construtiva, pressupõe a necessidade de transformar na escola/instituição de ensino o significado que é, geralmente, atribuído ao ato de avaliar. Implica mudar o conceito de avaliação, como a verificação de erros e acertos, seleção ou exame puramente classificatório, para outra concepção avaliativa, como reflexão 
contínua, cumulativa e integrada, de caráter formativo, como exercício de pensar sobre o pensar, de alunos e professores, a respeito de suas próprias construções e desenvolvimento. Quando voltada para o crescimento e para a melhoria da qualidade do ensino, a avaliação constitui-se em instrumento dialógico da construção do conhecimento de alunos e professores. Para tanto, é preciso mudar o paradigma da avaliação, isto é, alterar seu significado de restritivo para construtivo.

\section{Objetivos}

- Caracterizar a evolução das diferentes perspectivas da prática pedagógica e da avaliação no contexto educacional;

- definir o erro construtivo sob a perspectiva psicopedagógica, tendo por base os aportes teóricos da Psicologia Cognitiva, da Psicanálise e da Psicologia Social;

- identificar a abordagem metodológica para o desenvolvimento de uma avaliação construtiva, no âmbito do aproveitamento do aluno e da avaliação de disciplina;

- situar a metavaliação como processo de reflexão crítica e coletiva sobre a avaliação que se faz dos erros que surgem no processo de construção do conhecimento.

\section{Metodologia}

Este trabalho adota a pesquisa bibliográfica como procedimento de estudo para estruturar a revisão, análise e sistematização de conhecimentos já elaborados a respeito da avaliação, que incidem no processo de ensino e de aprendizagem. Baseia-se em contribuições que fundamentam e ampliam a reflexão sobre o tema, e que permitem explorar e interpretar a dimensão do "erro" implícito nesses processos. Apóia-se na concepção psicopedagógica que integra os pressupostos teóricos da Psicologia Genética, da Psicanálise e da Psicologia Social, numa perspectiva interdisciplinar.

\section{DELINEAMENTO TEÓRICO}

\section{Práticas Pedagógicas - Referenciais Históricos}

A avaliação inscreve-se nas práticas pedagógicas dos professores, nas instituições de ensino. 
Uma análise dos pressupostos teóricos subjacentes às condutas pedagógicas remete às teorias do conhecimento. Apresenta-se, então, a questão de quanto isto está claro para os educadores quando da tomada de decisões, tanto do ponto de vista prático como teórico.

O processo de educação/aprendizagem, inerente à dinâmica de transmissão da cultura, dá origem ao conhecimento como seu produto, possivelmente, mais evidente. Em decorrência disso, da busca por respostas a algumas indagações, surgem as diversas concepções de aprendizagem e práticas pedagógicas e de avaliação.

Mas o que é aprendizagem?

Toda aprendizagem é um processo complexo e contextualizado, que ocorre em determinado espaço e tempo delimitados. A aprendizagem escolar, por suas características próprias, difere da aprendizagem familiar, social e cultural.

Em diferentes momentos da história da educação na humanidade, encontram-se registradas diversas concepções (não tão diversas assim) do que é aprender.

Segundo Dorneles (1998) as funções cognitivas têm uma história e a capacidade de aprender tem-se manifestado desde os tempos préhistóricos.

Pesquisas revelam que datam de 30 mil anos os primeiros registros de quantidade e as primeiras pinturas rupestres, com objetivos que poderiam ser mnemônicos ou estéticos. Estudos sobre as pictografias antigas demonstram que, por trás desses registros, havia uma idéia, uma ação, em razão da necessidade de fazer perdurar os signos que a mente do homem foi criando. Refere-se, portanto, à capacidade simbólica que foi progressivamente se desenvolvendo.

Dentre algumas das civilizações antigas, os egípcios e os sumérios deixaram registros de sua história da educação. Por inferência, com base em tabuinhas encontradas, conclui-se que a repetição era o método de aprendizagem praticado e que o objetivo da aprendizagem era memorizar os textos por meio de cópia do material lido, constatando-se, portanto, que a aprendizagem por repetição e memorização é uma tradição muitíssimo antiga.

Como alternativas ao ensino memorístico, na Grécia Antiga, surge a escola de Platão e o método socrático, dialógico. Essa forma alternativa de conceber a aprendizagem era, no entanto, restrita a pequeno grupo de aprendizes e tinha como principal objetivo desenvolver o raciocínio lógico.

$\mathrm{Na}$ Idade Média, ainda que pouco conhecida quanto à aprendizagem, alguns registros da época mostram que a cópia dos textos 
religiosos era a principal prática de aprendizagem, restrita aos eclesiásticos. Olson (1997), pesquisador e estudioso do assunto, esclarece:

Assim como na Antiguidade, na Idade Média escrever significava escrever na memória. A leitura e a memorização eram ensinadas como se fossem a mesma coisa. Aprender a ler significava aprender um recurso que expandia a memória. Os textos escritos eram utilizados para conferir a memória, e não como objetos de representação.

(...)

O conhecimento residia na mente; a escrita era uma recordação, um recurso mnemônico. (p. 197)

O surgimento da tipografia permitiu certa liberdade da memória com relação aos textos escritos. Com a Revolução Industrial, emerge a importância da alfabetização e a necessidade de expansão da escola, a escola pública. O desenvolvimento da escolarização pública, segundo alguns autores, está relacionado à necessidade de instituir nova forma de treinamento social, para transformar os trabalhadores domésticos ou rurais em força de trabalho, a fim de atender às necessidades sociais $e$ econômicas.

Mantinha-se, portanto, a prática da memorização e repetição como geradora das aprendizagens.

Com base nos cenários até aqui apresentados, percebe-se que a nossa civilização tem uma tradição milenar de conceber a aprendizagem como um processo de memorização de conceitos, fatos e registros. Subjacente a esse fato pode estar a idéia de que aprender significa ter acesso a um conhecimento que é externo ao sujeito e que, portanto, precisa ser incorporado por ele, para que ocorra, realmente, o que se tem chamado de aprendizagem.

Tradicionalmente, a prática pedagógica acentua a transmissão de conhecimentos historicamente acumulados. O ensino é centrado no professor, aquele que detém o conhecimento, e ao aluno é destinado o papel de receptor passivo das informações que lhe são transmitidas. Privilegia-se o modelo pedagógico, o especialista e o professor. A preocupação é com a sistematização dos conhecimentos de forma acabada. As tarefas de aprendizagem, em geral, são padronizadas, no intuito de se conseguir a fixação de conhecimentos, conteúdos e informações. Há uma separação entre teoria e prática. A prática é a aplicação da teoria. Avanços teóricos, ocorridos com as mudanças no pensamento educacional e da própria conjuntura econômica, assinalaram inovações no âmbito da prática pedagógica. 
Sob o enfoque tecnicista, calcado em concepções de aprendizagem com base nos pressupostos experimentais comportamentistas (mudanças de comportamento), as práticas de ensino são norteadas pela tecnologia educacional e os planejamentos de ensino buscam atender à organização racional dos conteúdos, definidos de acordo com objetivos e habilidades que levem à competência. A teoria se subordina ao modelo científico, e a prática é vista como aplicação da teoria por meio da tecnologia educacional. Esse modelo implica na recompensa e controle, permanecendo a idéia de que o conhecimento é a cópia de algo que está no mundo exterior ao sujeito, e de que o indivíduo, sendo capaz de reproduzir informações, passos, tarefas e operações requeridas pelo perfil ocupacional, estaria qualificado para atuar no mercado de trabalho conforme o esperado.

As transformações que vêm acontecendo no mundo do trabalho e na organização social determinaram a revisão da ação educativa, em geral. Hoje, na sociedade em constantes mudanças, que ocorrem cada vez mais rapidamente, constata-se a exigência crescente por indivíduos capazes de produzir com mais eficiência e qualidade. A agilidade da comunicação, mediante recursos tecnológicos sempre mais avançados, requer do homem presteza e eficiência na apropriação e no processamento de informações, na sua transformação e subseqüente comunicação à sociedade, que assim constrói novos conhecimentos. São requisitos do novo profissional: capacidade de raciocínio abstrato, de autogerenciamento, de assimilação de novas informações; compreensão das bases gerais, aquisição de habilidades de natureza conceitual e operacional; domínio das atividades específicas, suas inter-relações e flexibilidade intelectual para lidar com as mudanças. Isso gerou o acirramento de posturas críticas em relação à educação. Entretanto, os esforços envidados até o momento não foram suficientes para a superação do enfoque tecnicista, que ainda predomina sob a influência das novas tecnologias.

Nesse cenário, outras práticas pedagógicas foram surgindo, buscando promover uma relação com os alunos de modo que o conhecimento passe a ser produto de pesquisas e experiências vividas e analisadas por eles, procurando desenvolver sua criatividade e autonomia. Constituem abordagens pedagógicas inovadoras à prática pedagógica tradicional e tecnicista, denotando um questionamento do papel da escola como instituição social que, como tal, impõe limites a outras possibilidades de prática pedagógica. Tais perspectivas, que têm por base teorias psicológicas, podem ser agrupadas segundo a ênfase dada ao indivíduo ou ao trabalho em grupo (Harper et al., 1980). Entre elas estão a Psicologia Genética, a corrente da evolução socioafetiva (sob influência da psicanálise e da psicoterapia), a que prioriza o desenvolvimento de uma vida em grupo 
em sala de aula, a Pedagogia Institucional e aquela que se concentra no questionamento do papel do professor. Essas orientações pedagógicas não são encontradas isoladamente, nem são conflitantes entre si, podendo coexistir no mesmo sistema educacional, na mesma disciplina, e, por vezes, na mesma instituição.

No decorrer da história da humanidade, são encontrados vários paradigmas explicativos do processo ensino-aprendizagem que reúnem grande variedade de enfoques e abordagens implícitas nas práticas pedagógicas. Contudo, é importante que se continue buscando ampliar e aprofundar o conhecimento a respeito da prática pedagógica e da aprendizagem, bem como sobre a avaliação que dela se faz, e seu significado social.

\section{Trajetória da Avaliação - Breve Viagem no Tempo}

A análise da avaliação da aprendizagem envolve ampla discussão sobre vários aspectos. Dentre eles, destaca-se a finalidade da avaliação que, por sua vez, não pode ser dissociada do tipo de aprendizagem a ser promovido. Estudos têm demonstrado a alta correlação entre a avaliação utilizada pelo professor e as estratégias de aprendizagem desenvolvidas pelo aluno. Para melhor entendimento desta relação e da evolução do conceito de avaliação como ação pedagógica, este trabalho supõe a necessidade de breve síntese histórica dos estudos de avaliação já realizados e seus pressupostos básicos.

As primeiras concepções sobre a avaliação da aprendizagem parecem relacionadas à idéia de medir. Por meio do estudo de alguns registros da Grécia e Roma antigas, revelou-se o emprego de exames, orais na maior parte das vezes, pelos professores da época. Em Atenas, Sócrates submetia seus alunos a inquéritos orais. Os chineses já utilizavam testes de seleção para a admissão ao serviço civil. É, portanto, bastante antigo o uso da avaliação como medida.

Na Idade Média, caracterizada por intensa aceitação de "verdades" pela fé, predominava o método racional (tradicional) e o respeito ao "argumento da autoridade"; logo, repetir integralmente o que se ouvia ou lia era a prova mais aceitável do saber, valorizando-se, assim, a atenção e a memória.

No século XIX, nos Estados Unidos, foi criado um sistema de testagem, sendo um dos pioneiros nessa área. Tinha como objetivo experimentar um método uniforme de exames para estudantes das escolas públicas de modo que avaliasse a qualidade da educação. A experiência resultou em algumas sugestões, tais como: substituir os exames orais pelos 
escritos; utilizar maior quantidade de questões específicas, em vez de poucas questões gerais; e buscar padrões mais objetivos do alcance escolar. Nasciam, a partir daí, os primeiros testes objetivos e exames estaduais e regionais.

Na Europa, em países como a França e Portugal, surge a Docimologia, a ciência do estudo sistemático dos exames, ou, especificamente, do sistema de atribuição de notas e dos comportamentos dos examinadores e examinandos. Esses trabalhos buscavam analisar as diversas variáveis que influem no ato de medir os conhecimentos. A partir de então, a evolução essencialmente conceitual da avaliação pode ser delineada em quatro gerações, conforme aponta Penna Firme (1999).

Durante as primeiras décadas do século XX, a avaliação educacional formal esteve associada à aplicação de testes, à tecnologia de mensuração das capacidades humanas, revestindo-se o processo avaliativo de um caráter instrumental, característica da primeira geração. Não havia distinção entre avaliação e medida.

Os estudos de Ralph Tyler inovaram essa idéia de mensuração com a concepção de que o processo avaliativo consiste basicamente em determinar em que medida os objetivos educacionais estão sendo atingidos pelos programas instrucionais. Nessa geração, chamada de descritiva, o avaliador preocupava-se em descrever padrões e critérios, embora ainda bastante técnico em sua atuação, influenciada fortemente pelo "modelo científico".

A geração seguinte, em razão de limitações observadas na fase anterior, quanto às dificuldades na definição a priori dos objetivos de ensino e quanto à necessidade de avaliar um programa antes de seu resultado final, para possibilitar correções e ajustes, surge mediante as análises de Stake e Scriven: o julgamento de valor como elemento essencial do processo avaliativo. Não bastava medir e descrever, era preciso também julgar.

Recentemente, a avaliação da quarta geração fica caracterizada pelo processo interativo, negociado, que se fundamenta num referencial teórico construtivista e num enfoque responsivo. Parte de preocupações, proposições ou controvérsias em relação ao objeto da avaliação. É construtivista uma vez que supera o modelo científico e tecnicista, predominante até então, abrangendo também os aspectos humanos, políticos, sociais, culturais e éticos, envolvidos no processo.

Vale ressaltar que, embora marcada pela flexibilidade, a concepção responsivo-construtivista não exclui os procedimentos do tipo ordenado, e cientificamente mais orientados, apenas os incorpora, desde que a 
responsividade e as preocupações das diferentes situações assim o exigirem.

Diante da diversidade e multiplicidade de modelos e abordagens avaliativas que os estudos e práticas têm produzido, é importante perceber, na trajetória da avaliação, assim como nas várias concepções da aprendizagem, ao longo da história humana e da educação, que as contínuas e progressivas mudanças na sociedade impõem outros desafios, como impulsionadores para novas concepções, que contribuam efetivamente para a melhoria da qualidade do ensino e da aprendizagem. Tornam-se necessárias novas conceituações e posicionamentos, uma vez que os paradigmas que ainda predominam não permitem lidar satisfatoriamente com os problemas e desafios atuais.

\section{A Virtude do Erro}

A revisão das práticas avaliativas remete, conseqüentemente, à reconceitualização do erro incorrido nas atividades de aprendizagem.

O que é erro de aprendizagem?

É uma idéia que tem sua origem no contexto da existência de um padrão considerado correto. No percurso do processo de aprendizagem, o erro, freqüentemente, aparece associado ao ridículo, à deficiência ou ao fracasso escolar.

Do ponto de vista psicopedagógico é outra a orientação a ser dada com relação ao erro escolar. A psicopedagogia prescreve uma postura construtivista do processo ensino-aprendizagem, destacando a importância de se construir uma prática educativa na qual se valorize a possibilidade de o aluno vir a aprender e se incorpore a não-aprendizagem como parte do processo.

A reconceitualização do erro no processo de aprender importa também em discernir o erro construtivo do erro sistemático. O primeiro é aquele que surge durante o processo de redescoberta ou reinvenção do conhecimento, e que o sujeito abandona ao alcançar um nível de elaboração mental superior. Já o erro sistemático é aquele que resiste, apesar das evidências que comprovam sua inadequação, limitando ou mesmo impedindo as possibilidades de aprendizagem. Do ponto de vista psicopedagógico, esse tipo de erro não é satisfatoriamente explicado, se for levada em conta apenas a Psicologia Genética. Faz-se necessário considerar a dimensão das significações inconscientes que inibem o mecanismo inteligente. Trata-se da dimensão afetiva; em outras palavras, da dimensão do desejo, que, de modo diferente do aspecto afetivo da conduta enunciado 
por Piaget, implica na abordagem psicanalítica do sujeito do saber, ou seja, sujeito do desejo.

Freud (1972), explica a curiosidade sexual das crianças nessa fase, enunciando o que ele chamou de instinto do saber.

Quase na mesma época em que a vida sexual das crianças atinge seu primeiro ápice (...) elas também começam a mostrar sinais de atividade que pode ser atribuída ao instinto do saber ou de pesquisa. Este instinto não pode ser contado entre os comportamentos instintivos elementares, nem pode ele ser classificado como pertencente exclusivamente à sexualidade. (...)

Não é por interesses teóricos e sim por interesses práticos que as atividades de pesquisa começam a desenvolver-se nas crianças. (p. 199-200)

$\mathrm{Na}$ construção do pensamento, revelam-se duas dimensões: conhecimento e saber, como produtos das estruturações da inteligência e do desejo. A compreensão, tanto das possibilidades quanto das impossibilidades das aprendizagens, requer a busca das relações que se estabelecem entre essas duas estruturações, que se processam de forma diferenciada.

É importante destacar a relação já estabelecida por Freud (1976) entre a curiosidade intelectual e a curiosidade sexual. Para ele, a mola que impele o desenvolvimento intelectual é sexual, conforme declara:

A segunda das minhas alegadas extensões do conceito de sexualidade encontra sua justificativa no fato revelado pela pesquisa psicanalítica de que todos esses impulsos afetuosos foram originalmente de natureza inteiramente sexual, mas se tornaram inibidos em sua finalidade ou sublimados. A maneira como os instintos sexuais podem assim ser influenciados e desviados thes permite ser empregados para atividades culturais de toda espécie, para as quais, realmente, prestam as mais importantes contribuições. (p. 50)

Invocando a noção psicanalítica do desejo, o erro nas aprendizagens pode ser visto como um sintoma, significante de "algo" que ocorre de acordo com mecanismos diversos daqueles responsáveis pelas estruturações da inteligência.

Outro importante aspecto implicado no processo de ensino e aprendizagem é que a relação do aluno com o objeto do conhecimento se dá, inclusive, com a mediação da figura do professor e, portanto, está estreitamente associada à dinâmica inconsciente das suas primeiras relações objetais e com os processos de sublimação e transferência aí envolvidos. Como enuncia Freud (1976): 
A transferência é meramente descoberta e isolada pela análise. Ela é um fenômeno universal da mente humana, decide o êxito de toda influência médica e de fato domina o todo das relações de cada pessoa com seu ambiente humano. (p. 54)

Na premissa construtivista, em que todo conhecimento pressupõe uma organização que é efetuada pelos próprios esquemas mentais do sujeito, o erro se inscreve nesse processo com uma função potencialmente construtiva quando se constitui em indicador de progressos na atividade cognitiva, sinalizando aspectos estruturais e processuais na formação de conhecimentos daquele que aprende, isto é, revelando a estratégia do aluno com relação ao objetivo de aprendizagem a ser alcançado, que envolve a sua compreensão e procedimentos adotados mentalmente para dominá-lo.

Nessa perspectiva, o erro revela, para aquele que aprende, a inadequação de seus esquemas e evidencia a necessidade da construção de outros e/ou a reformulação daqueles previamente existentes. Esse enfoque leva alunos e também professores a serem sujeitos de seus próprios processos de reconstrução do conhecimento.

Logo, a virtude do erro, na visão psicopedagógica, está na possibilidade de constituir-se em fonte de crescimento, para alunos e professores, uma vez que permite o reconhecimento de sua origem e dos procedimentos e mecanismos que o produziram. Desde que conscientemente elaborado, o erro torna possível a oportunidade de revisão e avanço, permite fazer uma síntese mental, integrando o fazer ao sentir, gerando o prazer e o criar na aprendizagem.

\section{A Avaliação Construtiva}

A ação de avaliar, em sentido amplo e genérico, faz parte do cotidiano do ser humano. Esta avaliação, embora assistemática, está presente com freqüência em diversos momentos e em diferentes aspectos da vida humana. É basicamente uma análise e julgamento de valor sobre o objeto da avaliação, seja ele a própria ação do indivíduo, a do outro, seja fatos ou situações vivenciados em seu ambiente.

A avaliação educacional, no entanto, é caracterizada como uma ação sistematizada, contínua, apoiada em determinados pressupostos teóricocientíficos e funcional, isto é, deve servir aos fins a que se propõe (Goldberg, 1979, p. 167).

No planejamento de uma avaliação, a abordagem metodológica a ser adotada torna-se, entre outras, decisão de fundamental importância, porque dela decorrem outras decisões subseqüentes, como, por exemplo, a 
indicação das técnicas e instrumentos de avaliação mais adequados à situação e ao seu objeto.

\subsection{Abordagem metodológica}

Como abordagens gerais da avaliação distinguem-se as abordagens quantitativa e a qualitativa.

Os pressupostos da abordagem quantitativa revelam forte influência positivista (relação causa-efeito), considerando a educação como um processo tecnicista, cuja preocupação é com a comprovação da medida em que os objetivos estabelecidos anteriormente foram atingidos.

Já na abordagem qualitativa da avaliação, são compreendidos, além dos objetivos pré-estabelecidos, os significados subjetivos relacionados a valores, opiniões e ideologias subjacentes à interpretação dos dados e informações coletadas. São também considerados os efeitos secundários da aprendizagem, não só a curto prazo, mas tanto quanto possível a longo prazo, bem como as limitações e os erros a que está sujeita a ação avaliativa. A ênfase é no processo, para permitir a informação necessária à reformulação da ação educativa (função formativa), com pluralidade e flexibilidade metodológica, que não se restringe aos pressupostos do modelo tecnicista (positivismo).

Como aponta Saul (1991) citando Gomez:

A avaliação centrada em processos é em si mesma um processo que evolui em virtude de descobertas sucessivas e de transformações do contexto. Supõe, pois, um enfoque seletivo e progressivo. (p. 47)

O propósito é compreender a situação objeto de estudo; a informação, resultante da avaliação, deve ser um instrumento útil e válido para a reformulação de interpretações e ações dos participantes do processo educativo. O relatório de resultados deve levar em conta diferentes perspectivas daqueles que participam das experiências educativas de modo que permitam a reorientação de suas práticas.

Convém ressaltar que essas duas abordagens gerais da avaliação, embora distintas, não são necessariamente excludentes, conforme esclarecem Dey e outros (1999, p. 7). Ambas podem ser contempladas num mesmo plano de avaliação, ainda que com a predominância de uma sobre a outra, segundo o design de avaliação adotado.

Uma avaliação com enfoque construtivo privilegia métodos qualitativos, embora possa utilizar evidências quantitativas em seu objeto de estudo. 


\subsection{Avaliação do aproveitamento do aluno}

Analisando-se a evolução histórica da avaliação, percebe-se que, atualmente, a compreensão das teorias da aprendizagem influencia fortemente na estruturação da avaliação.

O termo aproveitamento escolar ou aproveitamento do aluno na aprendizagem refere-se, como explicam Davis e Esposito (1990), às construções do conhecimento e a certo progresso entre as já elaboradas e (...) menos ao armazenamento de informações do que ao uso que se faz das mesmas (...) (p. 72).

Ao considerar, numa perspectiva construtivista, que o objetivo maior do ensino é promover condições favoráveis à solução de problemas, e ao pensar criticamente, cabe, então, à avaliação procurar verificar se o aluno é capaz de usar as estruturas do conhecimento e se sua resposta é influenciada por fatores motivacionais, afetivos e cognitivos. Contudo, a avaliação não é apenas um instrumento de verificação dos resultados da prática pedagógica, mas um instrumento dialógico e de diagnóstico, quando busca fornecer informações que subsidiem as decisões dos protagonistas da história da aprendizagem - alunos e professores possibilitando o reconhecimento da inadequação de seus esquemas, para sua reformulação e reconstrução de conhecimentos.

Nesse sentido, situam-se e ganham significado os objetivos desta avaliação: auxiliar o processo de ensino e orientar os alunos no seu processo de aprendizagem. Para tanto, a avaliação destinada a apoiar estes processos deve ocorrer em diferentes momentos, evidenciando sua característica formativa, visando, fundamentalmente, a propiciar uma regulação interativa, promovendo o autoconhecimento (auto-avaliação), o desenvolvimento da auto-estima, a colaboração ética e compromissada.

Contrariamente ao positivismo, na perspectiva construtivista, o conhecimento é construído a partir da experiência (ação); a realidade é produto da interação do indivíduo com o meio, o que significa haver não uma única realidade objetiva, mas diferentes concepções da realidade entre os indivíduos. Como implicação dessa premissa para a avaliação, está a importância de proporcionar diversas oportunidades para que o aluno demonstre sua capacidade, e aceitar, como evidências de aprendizagem, diferentes perspectivas de resultados como critérios de avaliação.

Considerando que aprender, ensinar e avaliar constituem um processo interativo, a seleção ou elaboração de técnicas e instrumentos de avaliação está claramente relacionada não só com o que ensinar, mas também com o como ensinar, isto é, deve levar em conta o tipo de aprendizagem a ser promovido. Entre os instrumentos mais indicados para 104 Estudos em Avaliação Educacional, v. 19, n. 39, jan./abr. 2008 
uma abordagem de avaliação qualitativa estão as entrevistas (individuais e coletivas), o portfólio ${ }^{1}$, itens de perguntas abertas, observações, dissertações, estudo de casos, etc.

No entanto, entre os estudiosos da avaliação, Hadji (1999) considera que (...) não há um instrumento de avaliação (...). Há apenas instrumentos que podem servir para a avaliação. Ele explica que (...) a virtude formativa não está no instrumento, mas sim, se assim se pode dizer, no uso de que dele fazemos (...) (p.32-35). Assim, o que mais importa, sob essa ótica, é que o instrumento selecionado ou construído permita, ao professor, investigar os erros dos alunos e melhorar as condições da aprendizagem.

Nessa perspectiva, diferentemente do professor cuja atuação está pautada em modelos do ensino tradicional, cabe ao docente definir novos padrões de avaliação que devem minimizar o memorizar simplesmente, enfatizando o exercício do pensamento e a habilidade de solucionar problemas. A elaboração consciente dos erros na aprendizagem, por parte do aluno, requer, também, o prévio conhecimento dos critérios de avaliação e o diálogo permanente com o professor, para favorecer a análise crítica de seu processo de construção do conhecimento.

Professores e alunos necessitam perceber os avanços na aprendizagem e isso deve ser o propósito fundamental da avaliação no processo de ensino e aprendizagem, caracterizado como de interação dinâmica em que os papéis freqüentemente se alternam. Aquele que ensina tem por seu objeto de conhecimento aquele que aprende e não o saber que deve transmitir. Nesse sentido, aquele que aprende também ensina. A relatividade desses papéis implica admitir um desequilíbrio momentâneo que conduz a uma experiência de aprendizagem mais rica e mais criativa de modo que se promova o desenvolvimento dos indivíduos e uma maior capacidade de aprender, transformando esse processo numa experiência de construção coletiva do conhecimento (Pichon-Rivière, 1991).

\subsection{Avaliação do desenvolvimento da disciplina}

Geralmente, mesmo de forma assistemática, os alunos avaliam a disciplina quando julgam o conhecimento que o professor demonstra em sala de aula, seu comportamento e suas atitudes. Os professores também avaliam a aula que deram, as atitudes e as decisões que tiveram de tomar perante os alunos. Mas é por meio do exercício de uma avaliação

\footnotetext{
1 Portfólio é um instrumento que compreende a compilação de todos os trabalhos realizados pelos estudantes, durante um curso ou disciplina. Inclui também ensaios auto-reflexos (Sousa, 1999, Mapa de Informação, 1.13, p. 1). 
intencional, sistematizada e contínua que se pode vivenciar um processo de responsabilidade compartilhada e consciente que leva ao crescimento.

A avaliação de disciplina, no que se refere ao trabalho do professor em sala de aula, é o meio pelo qual ele pode detectar evidências do seu bom ou mau desempenho no processo de ensino (Diniz, 1982, p. vi).

$\mathrm{O}$ caráter dialógico de que deve se revestir a avaliação permite $\mathrm{o}$ trabalho coletivo de avaliar a prática pedagógica, considerando seus erros e acertos para a reformulação de estratégias identificadas como deficientes no processo de ensino. Desse modo, os professores são levados a repensar alguns de seus (pré) conceitos, a rever métodos de ensino que adotam e a tentar outras técnicas e habilidades pedagógicas. A avaliação é o principal desconfiometro da competência humana (Demo, apud Lawrence et al., 2000, p. 12).

Algumas condições são reconhecidas como necessárias para a efetividade da avaliação de disciplina: a definição clara dos seus objetivos, a compreensão de que a disciplina faz parte de um curso (todo), o interesse e a motivação dos professores e da instituição em participar de todas as etapas do processo. Afinal, a qualidade da instituição é, em grande parte, atribuída ao crescimento profissional de seu corpo docente.

A eficácia de uma disciplina é determinada por vários fatores relacionados ao professor, aos alunos e ao contexto do curso e da instituição. No entanto, considera-se que a melhor medida da eficácia de uma disciplina seja a aprendizagem dos alunos, isto é, seu crescimento cognitivo e afetivo, os conhecimentos, as habilidades e competências que adquiriram. Ainda assim, estudos apontam que, na prática, quando esta avaliação é realizada, o interesse recai sobre a figura do professor e na utilização que faz de estratégias de ensino tidas como eficientes. Dessa forma, vale ressaltar a clareza necessária quando da definição dos objetivos da avaliação de disciplina, porque deles dependem as estratégias e técnicas a serem adotadas, o tipo e profundidade da análise e o uso que se pretende fazer dos resultados.

Normalmente, as informações obtidas nessa avaliação são utilizadas para auxiliar os professores a melhorar a sua prática pedagógica e para subsidiar decisões administrativas de pessoal, como aumento salarial ou promoções por mérito. Entretanto, como avaliação formativa, seu objetivo primordial deve ser auxiliar os docentes na melhoria do processo de ensino. $\mathrm{O}$ foco de interesse é a disciplina, em um ou mais aspectos, e não o professor.

Para avaliar o ensino, em alguma disciplina, é necessário estabelecer critérios bem fundamentados para que sejam confiáveis. A representação social do que vem a ser "bom ensino" ou "bom professor" deixa entrever 106 Estudos em Avaliação Educacional, v. 19, n. 39, jan./abr. 2008 
certas divergências. Contudo, distinguem-se alguns aspectos como indicadores importantes: a "sabedoria pedagógica" do professor, habilidade para articular interesses e condições prévias dos alunos, interação com a turma, habilidade para criar situações de desafio à aprendizagem, tipos de avaliação que adota, entre outros (Demo, apud Lawrence et al., 2000, p. 11-17). Aqui vale lembrar a proposta da avaliação emancipatória mencionada por Saul (1991) na qual enuncia os conceitos básicos envolvidos nessa modalidade avaliativa: emancipação, decisão democrática, transformação e crítica educativa, que podem nortear o estabelecimento desses critérios.

Ainda que a prática da avaliação de disciplina revele algumas dificuldades quanto à identificação do que seja "um bom ensino", há geralmente consenso a respeito do valor e significado da participação dos professores nesse processo de avaliação. Quanto maior sua participação no planejamento da avaliação, maior receptividade terão para o uso das informações de resultados. Essas informações, por princípio ético, se referem aos professores e somente devem ser repassadas a outros profissionais (inclusive o especialista em avaliação) e/ou a outras instâncias da instituição com sua prévia anuência.

É também consenso, entre os estudiosos desse assunto, a utilização de diversas fontes para a coleta de informações e o emprego adequado de múltiplas técnicas e instrumentos no processo de avaliação de disciplinas. Assim, podemos citar as classificações feitas pelos alunos em questionário de opiniões, a auto-avaliação do professor a partir do portfólio pessoal (diário reflexivo), o acompanhamento do aproveitamento dos alunos por meio de perguntas breves e diretas após a aula, a avaliação por pares e as entrevistas com os alunos.

O professor como avaliador, não só dos alunos, mas de seu próprio trabalho em busca de auto-aperfeiçoamento, torna-se um estímulo para que os estudantes participem mais amplamente do processo avaliativo, construindo-se, assim, coletivamente, uma cultura de avaliação em substituição à "cultura da prova". Abre, também, espaço para sua interação pessoal e respeito profissional entre colegas, propiciando uma melhor compreensão, dentro da instituição, do que seja a avaliação.

\section{CONSIDERAÇÕES FINAIS}

O cenário atual, sociocultural e econômico, das comunicações globais e dos velozes avanços tecnológicos, exige do homem novas formas de lidar com as transformações que vêm ocorrendo cada vez mais 
rapidamente. Prepará-lo para que seja capaz de atuar nessa realidade é um desafio social constante para a educação.

Apesar das muitas contribuições das correntes interacionistas e do esforço de abordagens pedagógicas inovadoras, a prática pedagógica em nossa realidade educacional ainda é marcada pela perspectiva tradicional de ensino e pelo tecnicismo, conforme relatam recentes pesquisas de estudiosos nessa área (Berger, 2000; Dorneles, 2001; Hoffman, 2000; Molina, 2000).

A avaliação da aprendizagem, como aponta Raphael (1999, p. 122), permanece centrada na reprodução de conhecimentos, pelos alunos, do modo como foram transmitidos pelo professor, com predominância da avaliação somativa, em detrimento da avaliação diagnóstica e formativa.

Buscando analisar essa situação, pesquisadores atribuem o fato à deficiência na formação do professor no que se refere à avaliação (Perrenoud, apud Berger, 2000) e ao despreparo com relação às abordagens teóricas subjacentes à sua prática. Segundo Davis e Esposito (1990):

(...) o que é surpreendente é que a formação recebida pelos docentes não os leve a atinarem para o fato de que seus parâmetros teóricos são absolutamente inconsistentes, acreditando, assim, utilizá-los com propriedade na avaliação do aproveitamento escolar de seus alunos. (p. 72)

Diante desse quadro, o distanciamento que se observa entre teoria e prática, entre o pensar e o realizar, parece não levar em conta que a relação entre teoria e prática, presente na atividade humana, é dialética, isto é, uma não pode ser compreendida sem a outra. Assim como não existe ação sem teoria (explicações, intenções, justificativas), também pode-se dizer que a teoria é fruto de ações já realizadas ou por realizar. Admitindo-se que a aprendizagem, de acordo com Pichon-Rivière (1991), implica uma relação dialética homem-sociedade, conclui-se, portanto, que essa relação deve permear, também, a prática avaliativa.

Outro aspecto a acrescentar a essa análise é o conflito de paradigmas instaurado na educação e na sociedade. As mudanças conceituais, geradas pela atual visão do mundo, abalam crenças e modelos estabelecidos, precipitando uma substituição de "verdades" na tentativa de se resolver os conflitos que, então, se instalam. Concordamos com Mamede Neves (1999) quando aponta para a interlocução, para o diálogo, necessários ao entendimento dos esquemas de significações dos personagens que atuam no processo educativo, e para o compartilhar de reflexões e representações construídas por meio da comunicação, como solução possível para esse conflito. Esse processo dialógico precisa 
estender-se, inclusive, às relações professor-aluno na aprendizagem e à relação destes com a instituição.

Nesse sentido, a avaliação passa a ser construtiva quando, primeiramente, erros ou acertos, sucessos e insucessos são acolhidos como tal (Luckesi, 1995), para permitir a compreensão da estrutura de significados que, desse modo, se revela, subjacente à trajetória percorrida pelo indivíduo na construção do conhecimento.

O desvendar do erro, que surge na aprendizagem e na prática pedagógica, pode vir a transformar o significado que comumente se dá à avaliação - medida de acertos e erros - pelo exercício contínuo da reflexão dialética e da relação dialógica entre avaliadores e avaliados, com uma postura de acolhimento, para se compreender as formas e caminhos alternativos buscados no desenvolvimento do processo de construção do conhecimento, contribuindo, dessa forma, para a construção de uma cultura da avaliação. Reside aí sua virtude: a possibilidade do resgate da premissa básica da avaliação - o questionamento - tornando-se, assim, ferramenta útil e valiosa para o crescimento.

A avaliação é considerada pelos autores de Taxonomia de objetivos educacionais como o nível mais elevado de cognição, situado no ápice de uma pirâmide de funções cognitivas. (Miller, s/d, p. 169)

A universidade, como instituição educacional destinada ao avanço e ao ensino da Ciência, tem como uma de suas principais finalidades a formação de profissionais com capacidade de investigação na sua área. Para isso, é preciso estimular, desenvolver, com os alunos, tarefas de investigação diversificadas, resgatando, assim, o instinto do saber ou de pesquisa de Freud, que se inicia na infância, mas que está presente em vários aspectos da vida social e tem importante expressão no processo de construção do conhecimento do indivíduo e da sociedade. Nesse processo se inscreve a metavaliação ${ }^{2}$ como reflexão crítica e coletiva dos possíveis erros que fazem parte do caminho, buscando promover a desejada superação das dificuldades e o desenvolvimento das potencialidades de cada um para o crescimento de todos.

Mudar padrões estruturados no início da vida é uma das lições mais difíceis de se aprender e de se ensinar. Geralmente, acreditamos que os hábitos seguidos durante toda uma vida não possam ser alterados e, portanto, sentimos que somos limitados em certos aspectos. No entanto, não existe realmente nenhuma limitação quanto ao

2 Metavaliação é a avaliação do valor e do mérito de uma avaliação (Sousa, 1999, Mapa de Informação 1.02, p. 1)

Estudos em Avaliação Educacional, v. 19, n. 39, jan./abr. 2008 
que podemos realizar, se apreciarmos, de verdade, todas as oportunidades que a vida nos oferece. Podemos romper com nossas limitações auto-impostas, fazer mudanças enormes e descobrir novas habilidades que nunca antes imaginávamos possuir. Mais importante ainda, podemos ganhar consciência das nossas verdadeiras responsabilidades. (Tarthang Tulku, mestre budista, in Luckesi, 1995, p. 156)

\section{REFERÊNCIAS BIBLIOGRÁFICAS}

BRADFIELD, James M.; MOREDOCK, H. Stewart. Medidas e testes em educação. Brasil: Fundo de Cultura, 1963. v. 1.

BERGER, Miguel André. Reconhecendo a avaliação da aprendizagem nos cursos de formação de professores. Set. 2000. Disponível em: <http://168.96.200.17/ar/libros/anped/0422T.PDF> Acesso em: 28 fev. 2001.

CADERNOS DE ESTUDO. Curso de psicopedagogia. Pós-graduação. Rio de Janeiro: UFRJ/CFCH, 1999.

DAVIS, Cláudia; ESPOSITO, Yara Lúcia. O Papel e função do erro na avaliação escolar. Cadernos de Pesquisa. São Paulo: Fundação Carlos Chagas, n. 74, p. 71-75, ago. 1990.

DEPRESBITERIS, Léa. Avaliação de programas e avaliação de aprendizagem. In: METS, Lisa A.; FRANCO, Maria Laura P. Barbosa. Avaliação de Currículos e Programas: leituras complementares. 2.ed. Brasília: Universidade de Brasília, v. 4, n. 19, 1999.

DEY, Eric L. et al. (orgs.). Técnicas e instrumentos de avaliação. 2.ed. Brasília: Universidade de Brasília, v. 2, 1999. 88p.

DINIZ, Teresinha. Sistema de avaliação e aprendizagem. Rio de Janeiro: Livros Técnicos e Científicos, 1982.

DORNELES, Beatriz Vargas. Escrita e número: relações iniciais. Porto Alegre: Artmed, 1998.

Uma perspectiva história da aprendizagem. Pátio: revista pedagógica. Porto Alegre: Artmed, ano IV, n. 16, p. 29-33, fev./abr. 2001. 
FREUD, Sigmund. Um estudo autobiográfico e outros trabalhos. Rio de Janeiro: Imago, v. 25, p. 11-197, 1976 (Pequena coleção das obras de Freud).

Três ensaios sobre a teoria da sexualidade. Rio de Janeiro: Imago, v. 7, p. 1-352, 1972 (Edição standard brasileira das obras psicológicas completas de Sigmund Freud).

GOLDBERG, Maria Amélia Azevedo; SOUZA, Clarilza Prado de. A Prática da avaliação. São Paulo: Cortez \& Moraes, 1979.

HADJI, Charles. Para escolher e utilizar instrumentos adaptados. In: SOUSA, Eda C. B. (org.) Técnicas e instrumentos de avaliação: leituras complementares. 2.ed. Brasília: Universidade de Brasília, IESB, v. 2, p. 3147, 1999.

HARPER, Babette et al. Cuidado, Escola! Documento IDAC. São Paulo: Brasiliense, n. 16/17, 1980. 117p.

HOFFMAN, Jussara Maria Lerch. Avaliação: mito e desafio - uma perspectiva construtivista. 28.ed. Porto Alegre: Mediação, 2000. 118p.

LAKATOS, Eva Maria; MARCONI, Marina de Andrade. Metodologia do trabalho científico. São Paulo: Atlas, 1992. 214p.

LAWRENCE, Janet H. et al. (orgs.) A Avaliação de disciplinas. 2.ed. Brasília: Universidade de Brasília, v. 3, 2000. 74p.

LINDEMAN, Richard H. Medidas educacionais. Porto Alegre: Globo, 1978. $176 \mathrm{p}$.

LUCKESI, Cipriano Carlos. Avaliação da aprendizagem escolar. São Paulo: Cortez, 1995. 180p.

MAMEDE NEVES, Maria Aparecida C. A Crise dos paradigmas em educação na óptica da psicologia. In: BRANDÃO, Zaia (org.). A Crise dos paradigmas e a educação. 5.ed. São Paulo: Cortez, 1999 (Questões de nossa época, 35).

MEDEIROS, Ethel Bauzer. Provas objetivas: técnicas de construção. 5.ed. Rio de Janeiro: Fundação Getúlio Vargas, 1977. 160p. 
MILLER, R. Diretrizes para o aperfeiçoamento do sistema de avaliação. In: SOUSA, Eda C. B. Avaliação de docentes e do ensino: leituras complementares, 2.ed. Brasília: Universidade de Brasília, v. 5, p. 167-184, s/d.

MIZUKAMI, Maria da Graça N. Ensino: as abordagens do processo. São Paulo: EPU, 1986.

MOLINA, Alexandra da Silva. A Questão do erro nas práticas pedagógicas: uma análise sócio-histórica. Mar. 2000. Disponível em: <http://fe.unicamp. br/alle/pub_tcc_inic.html> Acesso em: 08 mar. 2001.

OLSON, D. R. O Mundo no papel: as implicações conceituais e cognitivas da leitura e da escrita. São Paulo: Ática, 1997.

PENNA FIRME, Thereza. Avaliação: tendências e tendenciosidades. In: METS, Lisa A.; FRANCO, Maria Laura P. Barbosa. Avaliação de currículos e programas: leituras complementares. 2.ed. Brasília: Universidade de Brasília, v. 4, p. 103-113, 1999.

PIAGET, Jean. Seis estudos de psicologia. Rio de Janeiro: Forense, 1976. 146p.

PICHON-RIVIÈRE, Enrique. O Processo grupal. São Paulo: Martins Fontes, 1991.

POPHAM, William James. Como avaliar o ensino. Porto Alegre: Globo, 1976. $160 p$.

Manual de avaliação: regras práticas para o avaliador educacional.

Petrópolis: Vozes, 1977. 96p.

RAPHAEL, Hélia Sonia. Avaliação: questão técnica ou política? In: METS, Lisa A.; FRANCO, Maria Laura P. Barbosa. Avaliação de currículos e programas: leituras complementares. 2.ed. Brasília: Universidade de Brasília, v. 4, p. 115-127, 1999.

SAUL, Ana Maria. Avaliação emancipatória: desafio à teoria e à prática de avaliação e reformulação de currículo. 2.ed. São Paulo: Cortez, 1991. 151p.

SILVA, Mário Camarinho da; BRAYNER, Sonia. Normas técnicas de editoração: teses, monografias, artigos e papers. 3.ed. Rio de Janeiro: UFRJ, 1995. 
SOEIRO, Leda Ribeiro; AVELINE, Suelly. Avaliação educacional. Porto Alegre: Sulina. 1982. 240p.

SOUSA, Eda C. B. Machado de (org.). Mapas de informação. Brasília: Universidade de Brasília, 1999.

Recebido em: julho 2007

Aprovado para publicação em: outubro 2007 
